\title{
Edgar Morin, heterodoxo innovador. Un recuento de sus contribuciones a las Ciencias Sociales y a las Humanidades
}

Edgar Morin: heterodox innovator. An account of his contributions to the social sciences and the humanities

\author{
Enrique Luengo González \\ Centro de Investigación y Formación Social del ITESO-Universidad Jesuita de Guadalajara, México \\ luengo@iteso.mx
}

\author{
EDGAR MORIN Y EL PENSAMIENTO COMPLEJO \\ MONOGRÁFICO COORDINADO POR JOSÉ LUIS SOLANA RUIZ (Universidad de Jaén)
}

\begin{abstract}
RESUMEN
El artículo da a conocer la incansable, múltiple y larga trayectoria de Edgar Morin como uno de los grandes pensadores del siglo $\mathrm{XX}$, el cual, en su incesante búsqueda de un conocimiento no mutilado ni aislado, sino relacionado en conjuntos más amplios, ha realizado relevantes aportaciones a las ciencias sociales y a las humanidades en diversos ámbitos temáticos. Se destacan las contribuciones de Morin al método en las ciencias, su epistemología de la complejidad, sus novedosas maneras de proceder en la investigación empírica y sus sugerentes críticas a las metodologías estrechas de la investigación social. Se hace referencia a sus ensayos antroposociológicos de carácter inter y transdisciplinar, a su reconocimiento de la dimensión de la vida cotidiana y de la subjetividad, a sus propuestas innovadoras de políticas para la convivencia mundial, a las reformas que propone para enfrentar y construir nuestro futuro, y a su insistencia en la necesidad de transformar la educación para invitar a otras maneras de pensar y conocer. Morin no solo ha contribuido al conocimiento de las ciencias sociales; también es un humanista de la acción y del pensamiento, que se ha adherido a lo largo de su vida a lo que él ha entendido como causas justas y buenas de los seres humanos en nuestro planeta.
\end{abstract}

\section{ABSTRACT}

The article aims to present the tireless, multiple and long trajectory of Edgar Morin as one of the greatest thinkers of the twentieth century, who in his incessant search for an unmasked or isolated knowledge, but related in broader sets, has contributed to the Social Sciences and the Humanities in various thematic areas. His contributions have been about: on the method in sciences and the epistemology of complexity, on novel ways of proceeding in empirical research and suggestive critiques of the narrow methodologies of social research, on inter and transdisciplinary antroposociological works, on the recognition of the dimension of daily life and subjectivity, on innovative proposals for policies for global coexistence and reforms for better possibilities to face and build our future and on the indispensable need to transform education to invite other ways of thinking and knowing . Not only has Morin contributed to the knowledge of the social sciences, he is also a humanist of action and thought, who has adhered throughout his life to what he has understood as fair and good causes of human beings in our planet.

PALABRAS CLAVE

Edgar Morin | pensamiento complejo | Ciencias Sociales | Humanidades | complejidad

KEYWORDS

Edgar Morin | complex thinking | Social sciences | Humanities | complexity

\section{Introducción}

La intención de este escrito es ofrecer una panorámica sobre las aportaciones de Edgar Morin a las ciencias sociales y las humanidades. Una sencilla pregunta que guía el artículo es la siguiente: ¿cuáles son las contribuciones de la extensa obra de este pensador complejo al conocimiento de lo social y del ser humano?

Esta cuestión tiene sentido y es oportuna por varias razones. Una de ellas es el conocimiento parcial o relativo que se tiene de la múltiple obra de este gran pensador. Ante una trayectoria intelectual de más de sesenta años y una producción de varias decenas de libros es entendible que esto pueda ser así. La gran mayoría de quienes han escuchado hablar de Morin o lo han leído es posible que conozcan solo una parte de su extensa producción intelectual o alguna faceta de sus aportaciones, ya sea sobre la educación, la cultura de masas, la epistemología compleja, o bien lo identifican con ciertos principios básicos del pensamiento complejo (por ejemplo, el principio recursivo, dialógico y hologramático). 
Otra de las razones que me condujo a elaborar este escrito es que el conocimiento de las sui generis aportaciones de este pensador, es decir, de su trabajo transdisciplinar y complejo, nos invita a pensar y conocer de manera distinta a como convencionalmente se han venido desarrollando las tendencias dominantes en las ciencias que se abocan al conocimiento de lo humano individual y colectivo. Un tercer motivo, que me condujo a ofrecer un panorama sobre las contribuciones de Morin, se debe a que, si bien existen múltiples publicaciones enfocadas a dar cuenta en forma sintética de su obra o de una parte de ella, no abundan los escritos que hablen específicamente sobre sus diversas aportaciones a las ciencias sociales y las humanidades.

En relación con esto último, quisiéramos aclarar que no nos detendremos en la biografía ni en el contexto histórico o intelectual en el que Morin produjo su obra, pues estos aspectos han sido detalladamente descritos por él en varios de sus libros y entrevistas. Por el mismo motivo, tampoco nos abocaremos a hacer un resumen de su pensamiento, pues otros estudiosos lo han hecho con cierto detalle y amplitud. (2)

Sintetizar en unas cuantas páginas las aportaciones de este prolijo y activo pensador a las ciencias sociales y las humanidades no es tarea fácil, pues, cuando uno se encuentra ante la magnitud de la obra de intelectuales de tal talla, siempre se tiene la duda de las distorsiones que provoca la propia mirada, es decir, de identificar las principales preocupaciones o intereses personales con las aportaciones del autor que se estudia y admira. Afortunadamente, Edgar Morin, con su generosidad y humildad acostumbradas, leyó y dio su visto bueno a una primera versión de este texto (3). Este hecho me da pie a pensar que lo que planteo como contribuciones de Morin a las ciencias sociales y a las humanidades tiene un buen sustento, pero sería injusto por mi parte transferirle la responsabilidad de este escrito, pues, de hecho, la versión inicial la relaboré en su mayor parte, así como la bibliografía que presento al final del artículo.

\section{Edgar Morin heterodoxo, inconformista e innovador}

Bien se afirma que Edgar Morin es uno de los grandes pensadores del siglo XX y comienzos del XXI. Un hombre nacido y desarrollado en el cruce de diversas herencias culturales e intelectuales; un ser humano abierto y permeable a diversos afluentes. Este autor, heterodoxo, inconformista e innovador, no puede ser apropiado por una disciplina en particular ni por una corriente política en exclusiva. No obstante esta diversidad, existe un énfasis que da unidad a su producción intelectual. Tal como Edgar Morin lo indica en sus numerosos escritos, esta unidad consiste en sus aportaciones al pensamiento complejo. Su obra, por tanto, es un compromiso incesante con la búsqueda de un conocimiento no mutilado, no aislado, que respetando la individualidad y la singularidad de lo observado, lo inserta en circuitos de conocimientos más amplios para relacionarlo en contextos y conjuntos de mayor envergadura (Gutiérrez 2003: 20).

Para responder a la pregunta sobre los aportes de Edgar Morin a las ciencias sociales, las ciencias humanas y las humanidades es necesario, primeramente, clarificar lo que entendemos por estos ámbitos de conocimiento. Las ciencias humanas y las humanidades (4) pretenden buscar conocimientos y reflexionar sobre estos para ayudarnos a comprender quiénes somos, cómo hemos vivido juntos, cómo vivir en comunidad, cómo organizarnos para vivir mejor. En pocas palabras, son conocimientos que pretenden ayudarnos a vivir. Tal y como dice Carlos Eduardo Maldonado (2016: 13): "las ciencias sociales y humanas comportan en su seno, por lo menos en semilla, la idea de una cierta sabiduría de vivir". Por tal razón, en este artículo me pregunto sobre las contribuciones de Edgar Morin al conjunto de esas ciencias y disciplinas centradas en lo humano colectivo, que están imbricadas en su intento de explicar la complejidad de la condición humana.

Teniendo en consideración este breve preámbulo, como punto de partida, podemos afirmar que Morin, a lo largo de distintas etapas de su producción, ha ido contribuyendo destacadamente en los siguientes ámbitos de las ciencias sociales y las humanidades: (5)

1) La realización de investigaciones en temas de antroposociología contemporánea (6) y el cuestionamiento del proceder investigativo y de la conceptualización convencional de las ciencias sociales.

2) La búsqueda de un método capaz de enfrentar el desafío de la complejidad de lo real, no solo en lo referente al conocimiento científico, sino también a la complejidad de los problemas humanos, ambientales, sociales y políticos que nos retan continuamente. 
3) La incorporación de la dimensión biológica y de la dimensión imaginaria en la concepción de la complejidad antroposocial. Morin reconoce nuestra inserción y evolución físico-biológica y míticosimbólica e invita a tenerla presente en el autoconocimiento que los humanos tenemos sobre nosotros mismos, nuestro contexto y nuestra alianza con el universo.

4) La apertura de las ciencias sociales al reconocimiento de la dimensión de la vida cotidiana y de la subjetividad. Consiste en avanzar en un conocimiento de lo social y de lo humano que integre la dimensión del sentir y del significado que dan las personas a sus propias actuaciones. Aspecto que, en muchos casos, las explicaciones de las ciencias sociales no incorporan, han abandonado o desatendido.

5) El diagnóstico de los problemas fundamentales y de una propuesta ética para nuestro tiempo, relacionada con la propuesta de un conjunto articulado de reformas (del pensamiento, de la educación, de la ciencia, de la política, de la sociedad y de la economía) para enfrentar nuestro futuro.

6) Las reflexiones de Morin sobre el método del conocimiento y la complejidad, que lo llevaron a escribir una serie de libros y artículos sobre la necesidad urgente e imprescindible de reformar la educación.

7) El conjunto de estas aportaciones de Edgar Morin está alimentado y nutre, a su vez, su propuesta de un pensamiento complejo.

Morin es, sin duda, un producto de las tendencias dominantes y de las corrientes de pensamiento de su época, pero, a la vez, es productor de un conjunto de nuevas ideas resultantes del entrelazamiento de esos diversos afluentes (7). Pudiéramos preguntarnos sobre su originalidad o si fue el primero en expresar tal concepto o tales tesis. Sin embargo, lo que no sería justo es negarle la capacidad de ser un articulador e innovador de un conjunto de aportaciones para enriquecer las ciencias sociales y las humanidades. De hecho, cada vez que Morin aborda un problema social es para traducir su complejidad y expresarla en sus diversas dimensiones de análisis, pero sin perder de vista la organización o estructuración que lo sintetiza, incluyendo sus contradicciones, sus ambivalencias y su interacción con otros sistemas o contextos más amplios o de menor tamaño.

La gran curiosidad intelectual de Morin, su desintitucionalizada formación intelectual y su interés por "alimentarse omnívoramente", como él mismo señala en su autobiografía intelectual titulada Mis demonios (1995: 12 y 42), fueron componentes que le han permitido vincular una serie de aportaciones teóricas y conceptuales en tan vasta y diversa producción intelectual.

\section{Aportaciones de Edgar Morin a las Ciencias Sociales y a las Humanidades}

Las aportaciones de Edgar Morin a las temáticas antes señaladas se manifiestan y concretizan en su enorme producción intelectual. Intentaré en unas cuantas páginas la no fácil tarea de exponer las diversas contribuciones de este "pensador inconformista" a las ciencias sociales y a las humanidades. EI espacio del que dispongo en este artículo no me permite presentar ni siquiera una apretada síntesis de sus principales propuestas, por lo que solo enlistaré los conjuntos temáticos que Morin ha trabajado y algunas de sus principales obras.

Por otra parte, quisiera señalar que he decidido presentar la obra de este pensador francés a partir de un subjetivo criterio pedagógico, desde lo que considero que sería más fácilmente entendible para alguien no familiarizado con su obra hasta la propuesta más vasta y provocativa del pensamiento complejo.

\subsection{Aportaciones innovadoras en los procedimientos de la investigación empírica antroposociológica y críticas a las metodologías de investigación social estrechas}

Las investigaciones y los ensayos antroposociológicos de Morin destacan por ser estudios inter y transdisciplinarios que, orientados por los principios de la complejidad, combinan diversos procedimientos y técnicas de investigación con gran flexibilidad y rigor. Este es el caso de sus investigaciones sobre el impacto de la modernización en una pequeña comunidad (Comuna en Francia: La metamorfosis de Plozévet, publicado en 1967) y sobre un rumor antisemita en una ciudad de Francia (El rumor de Orleans, editado en 1969). Estas investigaciones aportaron, en su tiempo, novedosas y creativas formas de utilización e interrelación de diversas estrategias y técnicas de investigación.

Si bien muchas de sus primeras investigaciones empíricas fueron solicitadas por encargo, el hecho de realizarlas permitió a Morin repensar las formas de abordaje metodológicas y conceptuales. De ahí se 
desprende que en esos trabajos puedan apreciarse las agudas y atinadas críticas que Morin hace a las metodologías y herramientas convencionales de investigación social. La realidad, según él, es mucho más compleja y rica de lo que estamos dejando pasar por los procedimientos comúnmente utilizados en las ciencias sociales. Su libro Sociología (1984) recoge las propuestas y los cuestionamientos a la ciencia social, a sus conceptos y herramientas de conocimiento.

Otro ámbito de contribución, donde Morin ha sido muy activo a lo largo de su vida, es lo que él llama la sociología del presente. Se trata de diagnósticos sobre acontecimientos sorpresivos en la vida política y social que cuestionaban las interpretaciones o explicaciones de los sistemas de ideas convencionales que no los habían previsto con antelación (Morin 1994a: 36).

Desde mediados del siglo XX, Morin se ha aventurado a ese tipo de trabajos en diversos escenarios: la situación de Alemania inmediatamente después de la Segunda Guerra Mundial, el sentido de la revolución húngara, las consecuencias del octubre polaco, el Estado totalitario en la Unión Soviética, el alzamiento anticolonialista en Argelia, la expansión de la cultura de masas, las revueltas juveniles y el movimiento de Mayo del 68, la emergencia del neoruralismo y las nuevas corrientes ecológicas a partir de la década de 1970, el surgimiento de la Comunidad Europea, el sida y la sangre contaminada, la reacción de los "antisistema" contra el Grupo de los Siete en Seattle, la guerra fratricida en la antigua Yugoslavia, entre otras muchas aportaciones aparecidas en la revista Arguments, en artículos periodísticos en Le Monde (2014) o en libros publicados, como El año cero de Alemania (1946), El espíritu del tiempo (1962), Mayo 68: la brecha (1968), ¿Qué es el totalitarismo? De la naturaleza de la URSS (1983) y Pensar Europa (1987). En todos esos escritos, Morin ha destacado por ser un intérprete oportuno, actual y atinado en la interpretación de su tiempo.

La sociología del presente es un método en vivo de un suceso emergente y singular, que Morin propone en contraposición a la especialización disciplinaria y a los métodos de las ciencias sociales que buscan la regularidad de los fenómenos. El método en vivo, nos dice, es un compromiso del científico social con el acontecer contemporáneo y pretende atender al suceso marginal y polémico, así como a las crisis potencialmente reconstructoras de la vida social (Morin 1995: 186-191).

\subsection{Aportaciones al método y a la epistemología de la complejidad}

El método (6 tomos) es su obra mayor, ilustra la trayectoria de sus ideas e invita a la conciencia de un nuevo saber integrador. Esta magna obra está compuesta por los siguientes libros: La naturaleza de la naturaleza (t. 1) (1977), La vida de la vida (t. 2) (1980), El conocimiento del conocimiento (t. 3) (1986), Las ideas (t. 4) (1991), La identidad humana (t. 5) (2001) y Ética (t. 6) (2004), y se relaciona directamente con sus libros de corte epistemológico, donde hace referencia a su versión sobre la complejidad.

Bajo esta última temática se ubican textos tales como Ciencia con conciencia (1984), Sociología (1984), Argumentos para un método (Coloquio de Cerisy) (1990), Epistemología de la complejidad (1999), Inteligencia de la complejidad. Epistemología y pragmática (2006) y La aventura de El método (2015).

El método para Morin es una estrategia creativa y abierta del proceso de conocimiento que avanza y retrocede en la comprensión de sistemas u organizaciones complejas. Este proceso se orienta por algunos principios organizadores que permiten generar el conocimiento complejo (8).

De esta manera, la complejidad no solo tiene que ver con un incremento y una profundidad en el volumen de mayores interacciones entre los componentes de la organización o sistema que se pretende conocer, sino que comprende también las incertidumbres, los accidentes o azares, las indeterminaciones y las innovaciones que se vinculan y que explican el constante movimiento entre el orden y el desorden de los fenómenos que se estudian.

En cuanto a su epistemología, que sustenta sus planteamientos, Morin (2013: 135-157) considera los cuestionamientos y las nuevas propuestas que hacen distintas ciencias y posturas filosóficas al modelo clásico de ciencia (por ejemplo, Bergson, Bachelard, Piaget, von Neumann, von Foerster, Popper, Holton, Khun, Lakatos, Husserl). Propone sustituir unos principios simples del conocimiento por otros de mayor complejidad. Esta apuesta le permite proponer un nuevo paradigma (el paradigma del conocimiento complejo, donde sujeto y objeto se interproducen, reformulándose) y oponerse a la división y simplificación del pensamiento.

Relacionado con su propuesta epistemológica, Morin realiza una reconstrucción sistémica, sustituyendo objetos sociales fragmentados por problemas entendidos como sistemas complejos, lo que implica la 
necesaria recurrencia e intervención de diversas disciplinas para su abordaje. Es decir, Morin nos propone que los objetos de las ciencias de lo humano colectivo no deben cerrarse; por el contrario, tienen que comunicarse con las demás ciencias, identificando los vínculos que mantienen entre sí. Esta reconstrucción sistémica conduce a Morin a proponer una teoría de la organización, que, retomando las aportaciones de las distintas vertientes del pensamiento sistémico, contribuye a explicar el continuo proceso entre orden, desorden y organización.

\subsection{Aportaciones antroposociológicas de carácter inter y transdisciplinario}

Uno de los aportes de Morin a las ciencias sociales es la crítica que hace a su institucionalización. Según él, esas disciplinas han eliminado la complejidad antroposocial, al considerar la sociedad como un sistema cerrado, separado de la física, de la biología, de la psicología, de la evolución histórica de la especie homo y del mundo mágico-simbólico que ha acompañado a la humanidad desde los tiempos más remotos. También ha insistido en el riesgo que representa el hecho de que en el interior de las ciencias sociales y humanas se estén multiplicado las especializaciones, pues nos aleja de la posibilidad de captar la multidimensionalidad de los fenómenos sociales y de lo humano como unidad compleja.

El desarrollo de las ciencias físicas y biológicas ha permitido ampliar el conocimiento de nuestros orígenes. Si se atiende a los avances del conocimiento sobre el proceso plural y múltiple de la evolución, se puede deducir que no somos una especie privilegiada y metabiológica, sino una especie con antecedentes cósmicos y animales que no podemos ocultar y que son parte de nuestra condición humana (Gutiérrez 2013: 29).

La concepción de la sociedad como no exclusivamente humana es una aportación más de este lúcido pensador a las ciencias sociales y humanas. Morin insiste en el hecho de que la sociedad no nació con los seres humanos. Es decir, el fenómeno social es más antiguo y compartido de lo que solemos creer, evolutivamente ha estado presente antes de que surgiéramos como especie homo y está vivamente activo en la sociabilidad animal e incluso vegetal, como además han demostrado científicos recientemente (véase Maldonado 2009).

Si tomamos conciencia de esta idea, el concepto de las ciencias sociales y humanas cambia de perspectiva y permite destacar la originalidad y unicidad de lo humano como ser antroposocial, considerando su composición como especie, individuo y sociedad. Así, la intercomunicación y transversalidad de los saberes físicos, biológicos, antropológicos y sociológicos de lo humano individual y colectivo se tornan una guía prometedora para nuestro propio conocimiento y, en consecuencia, una mayor toma de conciencia sobre nuestro lugar y compromisos éticos en el mundo.

Por tanto, dado que la realidad física y biológica participa de la constitución de lo humano individual y social, se requiere otro tipo de conocimiento y de investigación. Al menos necesitamos un conocimiento articulado inter y transdisciplinario para disponer de otras visiones y valoraciones, para provocar y desencadenar otros conocimientos más allá de las fronteras tradicionales de las ciencias y las disciplinas, para obtener otras capacidades de respuesta y buscar alternativas creativas ante nuestros problemas y formas de vida. De no proceder de esa manera, estaríamos negando el recurrente hecho de que "un pensamiento mutilante, conduce, necesariamente, a acciones mutilantes" (Morin 1990a: 34). O bien, como afirma Gómez del Llano (2005: 13), que "cuando se piensa mal, se obra mal, y cuando se obra mal y se piensa mal de forma generalizada, no tarda en producirse la catástrofe". Es decir, evitar pensamientos y actividades disparatadas, descontroladas y con repercusiones y consecuencias no deseadas, alejadas de los problemas que en inicio se deseaban atender.

La inter y transdisciplina (9), según Morin, exigen a los científicos e investigadores cultivar el arte de concebir la manera de hacer investigación (cualidades requeridas para responder a la complejidad de los problemas abordados), el arte del diálogo (el movimiento organizador-creador del pensamiento entre los que participan en la investigación) y el arte estratégico de la investigación (considerar los efectos de las acciones y los potenciales resultados de la investigación desde una perspectiva ética y desde lo que Morin denomina ecología de la acción) (Barrón 2013: 137-138).

Algunas de las obras más destacadas y reconocidas de Morin en esta perspectiva inter y transdisciplinar, donde también refleja su capacidad innovadora, al iniciar y abrir una serie de temas de investigación novedosas para su época, son El hombre y la muerte (1951), El cine o el hombre imaginario (1956), Las estrellas (1957), La unidad del hombre (1978) y El paradigma perdido (1973). Particularmente, para conocer su concepción y sus propuestas sobre las ciencias sociales, es importante mencionar su libro Sociología, en el cual hace una revisión de conceptos tales como sociedad, ciencias sociales, sociología, 
ecología social, cultura, acontecimiento social, crisis, reorganización social, método de la complejidad y, además, lleva a cabo una serie de ejercicios de sociología del presente a partir de algunos objetos y fenómenos cotidianos.

\subsection{Apertura de las ciencias sociales al reconocimiento de la dimensión de la vida cotidiana y de la subjetividad}

Morin ha insistido en la necesidad de la apertura del pensamiento de las ciencias sociales al acontecer de la vida cotidiana y a otras formas de conocimiento, como la literatura, el cine y la poesía, pues son un mundo en el que se anudan, sin negarse, lo singular concreto de las personas y el conjunto general de lo social. Invita a buscar en esa articulación una riqueza que las ciencias sociales solas no pueden expresar. Algunos libros donde aparecen esos nexos son El cine y el hombre imaginario (1956), El espíritu del tiempo (1962), Amor, poesía y sabiduría (1997), Sobre la estética (2016) y, particularmente, en la teorización que hace de todo ello en El método IV: las ideas (1991).

El mito y lo imaginario, así como su relación con la afectividad, tienen un lugar fundamental dentro de la antroposociología de Morin. El ser humano no se define solo por lo racional, sino también por lo simbólico. En otras palabras, el mundo de las ideas, la noosfera como Morin la llama, es una realidad producida y creada por los humanos, que adquiere vida propia y se nos impone como algo externo a nosotros mismos. En nuestra subjetividad, manifiesta en nuestro transcurrir cotidiano, están presentes los mitos. Tal como afirma uno de los comentaristas más lúcidos que he conocido sobre la obra de Morin, Alfredo Gutiérrez (2003: 33-44):

"No hay que simplificar y creer que los mitos son mentirosos. Crean ilusión y permiten la mentira porque 'son verdaderos', verdaderos en el sentido en que un gran mito lleva, concentra y transmuta en sí las aspiraciones profundas que no son solamente de una época y de una sociedad, sino también de carácter antropológico (...). En consecuencia, no se trata de desmitificar (revelar la mentira en su uso), no se trata de desmitificar (pues no solamente estos mitos contienen nuestras 'verdades', es decir, nuestras aspiraciones, sino que, no podemos vivir sin mitos), se trata de considerarlos en su complejidad y de trabajar con/contra ellos". (10)

Por otra parte, es importante destacar que, como ya se habrá deducido, la contribución y actualidad de Edgar Morin es múltiple. Así, como profundo admirador del iniciador del ensayo, Michel de Montaigne, no es de extrañar que Morin haya desarrollado tal tipo de estilo literario y tenga la costumbre de escribir sus reflexiones y observaciones que diariamente le siguen sorprendiendo e interrogando (Morin 2013: 4347).

En ese conjunto de escritos, Morin ilustra el trayecto de sus reflexiones, revisiones o, aún, rectificaciones de su propia obra a partir, no solo de sus lecturas y aprendizajes intelectuales, sino también de su propia experiencia y contexto de vida. Sus escritos de corte autobiográfico y los diarios que hablan de sus reflexiones y sentimientos manifiestan la relación de su pensamiento con su subjetividad. En ellos, Morin reconoce que su andadura le ha llevado a enmendar sus posturas, a incorporar nuevos elementos y a elaborar reorganizaciones sucesivas de su pensamiento. En una de sus obras autobiográficas, titulada Mis demonios, relata las tres grandes etapas reorganizadoras de su pensamiento, donde ha tenido que desechar ideas previas e incorporar otras nuevas en su sistema de pensamiento (Morin 1994a: 202-217). (11)

En este grupo de escritos, además del libro antes citado, encontramos Autocrítica (1959), La vida del sujeto (1969) (12), Diario de California (1970), Diario de un libro (1981), Vidal y los suyos (1989), El año Sísifo (1995), Llorar, reír, comprender (1996), Edwige, l'inseparable (2009). Estos libros, como el conjunto de la obra de Morin, ofrecen un acervo diverso y profundo, gestado a partir de su propia experiencia vital.

\subsection{Aportaciones innovadoras de políticas para la convivencia mundial y reformas para enfrentar los problemas fundamentales de nuestro tiempo y construir nuestro futuro}

Edgar Morin, a lo largo de los años, ha continuado avanzando en la aplicación de ciertos principios del pensamiento complejo, lo que le ha permitido abordar tanto la realidad del presente como diversos sucesos singulares que le han interesado.

Morin concibe las políticas y necesidades de reformas de la sociedad, no en un sentido estrecho, sino como la configuración del espacio de lo público, constituido por múltiples interretroacciones en diferentes 
escalas geográficas -desde lo local a lo planetario-, donde intervienen, en distinto grado, múltiples actores sociales. Se trata de una nueva política o, más bien, como él la denomina, de una ántropopolítica, que responda a los tres componentes interrelacionados de lo que es el ser humano: individuo, sociedad y especie. Pues, paradójicamente, los humanos hemos sido productores y reproductores de la vida, pero también somos su principal amenaza y potenciales destructores. El urgente llamado que nos hace Morin es para preguntarnos si ya hemos cruzado el umbral crítico de nuestro engañoso dominio sobre el planeta e interrogarnos sobre cuándo detendremos la acelerada marcha hacia la autodestrucción de nuestra especie, los demás seres vivos y la biosfera, nuestra casa terrestre.

Las preguntas anteriores le llevan a Morin al convencimiento de que debemos abocarnos a proponer otros porvenires menos agresivos y fatales, pues la sobrevivencia nos exige modificar el devenir; por ello, propone multiplicar alternativas y efectuar reformas de distinto calibre que permitan guiar nuestra humanidad y civilización. Esto significa, entre otras cosas, la posibilidad de transformar nuestra concepción y nustras acciones en torno a la participación política, las relaciones con la naturaleza, la economía con visión social, la distribución de la riqueza, el acceso a la medicina y la salud, la manera de habitar la ciudad, la cultura de la alimentación y del consumo, los apoyos para las familias y las disposiciones para cada grupo de edad desde la niñez hasta el envejecimiento, etc. (Morin 2011).

Su interés y compromiso con una nueva política para la convivencia mundial y una visión de desarrollo distinta a la dominante, que considere una biopolítica o una política para potenciar la vida, dieron pie a sus libros Introducción a una política del hombre (1969), Para salir del siglo XX (1982), Tierra-Patria (1993), Política de civilización (1997), El año I de la era ecológica (2007) y Ecologizar al hombre (2016). Posteriormente, ha continuado publicando sobre el tema, proponiendo una serie de reformas para posibilitar la sobrevivencia de la vida humana rodeada de riesgos e incertidumbres, así como de otros seres vivos que nos acompañan y del conjunto de nuestra Tierra-Patria, tal como lo escribe en sus libros La vía para el futuro de la humanidad (2011) y El camino de la esperanza (2011).

Y ya que mencionamos la esperanza, quisiera detenerme en una cita de Morin, donde refiere que su interés por abocarse a los problemas fundamentales de su tiempo conlleva el compromiso por oponerse a toda forma de crueldad en el mundo y por facilitar lo mejor de la bondad del mundo:

"Resistir, resistir primero a nosotros mismos, nuestra indiferencia y nuestra falta de atención, nuestro cansancio y nuestro desaliento, nuestros malos impulsos y mezquinas obsesiones. Resistir por/para/con amistad, caridad, piedad, compasión, ternura, bondad. La resistencia a la crueldad del mundo debe intentar mantener la unión en la separación, atar lo que es libre dejándolo libre (...). Proseguir el esfuerzo cósmico desesperado que, en el humano, toma la forma de una resistencia a la crueldad del mundo es lo que denominaría esperanza" (Morin 1994a: 290-291).

\subsection{Aportaciones en torno al pensamiento complejo}

Morin desarrolla los principios del pensamiento complejo para resignificar el conocimiento y, así, facilitarnos el avance hacia una más y mejor ciencia con conciencia. Entiende su contribución como una oportunidad ética de mayor conocimiento intercultural, internacional e interpersonal. De esta manera, sus aportes son una posibilidad para la fraternidad, sin prejuicios ni exclusiones, de la común ciudadanía terrestre, de la amistad ilustrada en la democracia cognitiva, del conocimiento transdisciplinar y del pensamiento complejo. Por estas razones, algunos de los conocedores de su obra piensan, no sin razón, que el siglo XXI será el siglo de su obra.

Reiteramos que la apelación a una ciencia con conciencia nos permite pensar y conocer, distintamente a como lo hemos estado haciendo, las dimensiones interactivas y relacionadoras de la realidad. Esa apelación tiene también la intención de liberar el pensamiento solidario y el conocimiento compartido. Es decir, pensar y conocer complejamente para entender de otro modo nuestro actuar entre los humanos y nuestra relación con la naturaleza -con la propia y la de otros-. Pensar y conocer uniendo lo que está separado es una apuesta por la fidelidad a la vida.

La consigna del pensamiento complejo, nos dice Alfredo Gutiérrez, "podría decir: más conocimiento, siempre, pero con más conciencia", y añade: "No es igual saber más que saber mejor; saber para el presente que saber para la sucesión generacional; saber para nosotros sin saber para la Tierra. Saber solo lo nuestro sin ocuparnos del saber de los demás, democratizando la fuerza del conocimiento, advirtiendo de los riesgos del conocimiento mismo, asegurando los derechos de vida del conjunto humano por medio de una información científica oportuna y universal" (2003: 19). 
Por ello, se afirma que Edgar Morin es un pensador avanzado para nuestro tiempo y nuestros problemas; su obra es y será un recurso necesario, entre otros, para sobrevivir ante los desafíos que nos amenazan y ante el riesgo que significamos nosotros mismos, los humanos, para la existencia de otras formas de vida en la Tierra. Morin es el autor de una obra que contribuye a abrir la mente del siglo a las armonías y dificultades de la convivencia humana, de la ciencia y del arte del pensamiento complejo. Su contribución intelectual sobre el conocimiento, la comprensión y la solidaridad, junto a su insistencia en la interacción de los hechos -que no se deberían aislar de su contexto-, forman parte de un circuito que nos convoca e involucra a cada uno de nosotros.

\subsection{Aportaciones para transformar la educación y poder pensar y conocer de otra manera}

Las diversas contribuciones a las ciencias sociales y las humanidades, que he intentado sintetizar en este escrito, llevaron a Morin a la conclusión de que no solo era necesario conocer a partir de otros principios epistemológicos y metodológicos, sino que era urgente una reforma del pensamiento, la cual, a su vez, requería de una reforma de la educación en todos sus niveles educativos. Morin (1993: 192) afirma con contundencia que "la reforma del pensamiento es un problema antropológico e histórico clave. Esto implica una revolución mental todavía más considerable que la revolución copernicana. Nunca, en la historia de la humanidad, las responsabilidades del pensamiento fueron tan abrumadoras. El nudo de la tragedia también está en el pensamiento".

El camino recorrido por él, confiesa, lo condujo a ese convencimiento. Para pensar, conocer y actuar de otra manera, es decir, complejamente, requerimos fortalecer o modificar ciertos contenidos educativos, precisamos una reorganización de las instituciones educativas y los curricula, para que faciliten la articulación de los conocimientos, de reformas en la formación docente y la didáctica, de una transformación en las relaciones que se establecen entre los procesos educativos y las problemáticas sociales del entorno; necesitamos nuevas formas de educación permanente y de difusión de la ciencia y la cultura a las poblaciones no escolarizadas.

Esta faceta educativa de los aportes de Morin es, con mucho, la más conocida. Sus libros La cabeza bien puesta (1999), Religar el conocimiento (1999), Educar para la era planetaria (2003), Enseñar a vivir. Manifiesto para cambiar la educación (2014) y Los siete saberes necesarios para la educación del futuro (1999), este último escrito a solicitud de la UNESCO, han tenido una amplia acogida entre los educadores y el público en general.

\subsection{Otras múltiples contribuciones relacionadas con las Ciencias Sociales y las Humanidades}

Las aportaciones de Morin no se circunscriben al ámbito de la filosofía o las ciencias, sino que se amplían a través de la divulgación y el debate de sus ideas, de su ejemplar liderazgo intelectual, y del humanismo que conllevan su acción y su pensamiento.

Su producción editorial no solo consiste en profundos y bien argumentados textos destinados a lectores con formación científica o universitaria, sino que tiene la característica de ser vibrante y emocional, lo que le ha permitido transmitir su pensamiento relacionado con las ciencias sociales y humanas a sus lectores y público habitual. A mi parecer, algunos de los libros de Morin con esas características son ¿Cómo vivir en tiempos de crisis? (1990), ¿Hacía el abismo? Globalización en el siglo XXI (2007), El camino de la esperanza (en colaboración con Stéphane Hessel) (2011) y la obra anteriormente mencionada, TierraPatria (1993), que es una de las más conocidas. Habría que sumar a esta lista una diversidad de artículos en revistas no especializadas y en periódicos como Le Monde. Con la sencillez que lo caracteriza, Morin siempre ha estado interesado y dispuesto al debate y a la socialización colectiva de su obra, invitando al público, que lo escucha y lee, a cuestionar sus propias certezas, pues entiende su obra como siempre inconclusa.

Morin es un humanista de la acción y del pensamiento. En él encontramos una adhesión a las causas justas y buenas del planeta, oponiéndose de manera consistente a la crueldad del mundo, a los odios nacionalistas e interreligiosos o de otro tipo, a los prejuicios y al juicio apresurado que condena sin entender (Gutiérrez 2007: 59). A lo largo de su vida, ha resistido a los dogmas y fanatismos, manteniendo su compromiso con la libertad. En los difíciles momentos del contexto social que le ha tocado vivir, Morin ha actuado coherentemente, apegándose a distintas causas. Así, ha sido combatiente voluntario de la resistencia clandestina francesa durante la Segunda Guerra Mundial, miembro del movimiento de resistencia de prisioneros y deportados a los campos de concentración nazis, integrante del Partido Comunista Francés en la década de 1950, del cual fue excluido como "disidente cultural", defensor de la revolución antisoviética húngara de 1956, crítico maduro de las organizaciones e 
ideologías totalitarias, cofundador del comité contra la guerra en Argelia, promotor pacifista de un diálogo para detener y reconciliar los efectos de la guerra entre Serbia y Bosnia, opositor de la guetización de los palestinos, convocante de una conferencia internacional de alto nivel -lamentablemente no realizadapara analizar e intentar acuerdos sobre Oriente Medio.

Por otra parte, como buen humanista, Morin ha repasado el mapa de la evolución humana, abriendo un camino para que los hombres y las mujeres nos contemplemos con un mismo origen cósmico, terrícola, biológico y humano común. Esta vía de comprensión, a la cual nos invita, nos facilita admirar nuestra diversidad de culturas, nos impulsa a la fraternidad y es una guía para la interrogación del mundo y de lo que estamos haciendo con él. Así, hay quien afirma que Morin es "un autor militante del amor, la comprensión y el perdón entre los humanos" (Gutiérrez 2007: 60). Reivindica el derecho a ofrecernos distintas respuestas a la incertidumbre y al misterio de nuestro existir, sin temor a las preguntas fundamentales. Además, invita a asumir, en esas respuestas, lo imposible, si es necesario, y hacerlo posible mediante el conocimiento y la imaginación. Esta es la invitación permanente de este multiplicador de preguntas, que tiene la pretensión de abrir territorios e iluminar el interior de los humanos.

Por último, otro aspecto de su contribución es el liderazgo de Edgar Morin, que ha sido patente en distintas etapas de su vida y se refleja en las actividades y los compromisos que asume. A una edad temprana, con solo 22 años, se convirtió en uno de los líderes del movimiento de resistencia al nazismo en Francia, teniendo a su cargo grandes responsabilidades. Este hecho le fue reconocido, posteriormente, otorgándosele la distinción de Commandeur de la Legion d'Honneur por parte del Gobierno francés. Por otro lado, el liderazgo intelectual de Edgar Morin puede ser constatado no solo a través de las diferentes iniciativas en las que ha participado para crear diversos grupos, asociaciones y centros de reflexión, intercambio de ideas e investigación, sino también en el hecho de ser una figura central en diversos coloquios y seminarios internacionales. Otra clara evidencia de su presencia y valía intelectual es creación por la UNESCO de una cátedra con su nombre: Cátedra Edgar Morin para el pensamiento complejo.

Sobre el primer aspecto arriba mencionado, un ejemplo de su capacidad de iniciativa y de liderazgo es que, junto con los Premios Nobel Jacques Monod y Francois Jacob, fundó el Centro Internacional de Estudios en Biología y Antropología Fundamental, que se convertiría con los años en el Centro Royamunt para una Ciencia del Hombre.

En lo que respecta a sus cargos, Morin ha sido director de la revista Arguments, director de la revista Communications, codirector del Centro de Estudios Transdisciplinarios (en sociología, antropología y política) en la Escuela de Altos Estudios en Ciencias Sociales (EHESS), presidente de la Agencia Europa de la Cultura (UNESCO), presidente de la Asociación para el Pensamiento Complejo, presidente de Honor del Centro de Epistemología y Antropología Compleja de la Facultad de Letras de la Universidad de Bergamo, y presidente del Instituto de Ciencias Sociales de la Comunicación del Centro de Investigación Científica (CNRS).

Debido a la creatividad y novedad de sus ideas, Morin ha sido una figura que convoca al diálogo y al debate. Específicamente, en lo que se refiere a sus ideas en torno a las ciencias sociales y las humanidades, podemos mencionar diversas publicaciones que revelan las pertinentes discusiones que ha mantenido con científicos e intelectuales de distintos campos del conocimiento. Diversas publicaciones de esos intercambios dan cuenta de lo anterior, como, por ejemplo, Diálogos sobre la naturaleza humana con Boris Cyrulink (2000), Planeta, la aventura desconocida con Chrisophe Wulf (2002), La violencia del mundo con Jean Baudrillard (2003) y el intercambio de ideas sostenido con Hubert Reeves y Monique Mountier-Khun en torno al hombre, el universo y la ciencia, con Francois Ewald sobre la complejidad y la conciencia de la incertidumbre, y sobre educación y complejidad con Jacques Ardoino (1999) (13). También, destacan en esa línea el coloquio que le dedicó y organizó JeanLouis Le Moigne para discutir sobre la ciencia y la conciencia de la complejidad, así como los coloquios La unidad del hombre (1978) y Argumentos para un método (1990), donde diversos convocados debatieron sus ideas.

\section{Conclusiones y aperturas}

A lo largo de la obra multiforme, rica y diversa de Edgar Morin encontramos una constante que le da unidad y coherencia: la complejidad, lo tejido en conjunto. Por esta razón, Morin es identificado como un articulador del conocimiento, un integrador de saberes, un incesante practicante de la interdisciplina y la 
transdisciplina, así como un incitador para reformar los procesos educativos que parcializan los conocimientos.

Su tarea, así la concibe él, es ser un reorganizador del conocimiento, para anudar cabos antes sueltos y poder desprender otros significados que nos permita actuar con más conciencia sobre nuestras vidas y el conjunto de nuestro planeta. De esa manera, nos dice, podemos evitar ser víctimas y quedar irremediablemente atrapados por las realizaciones de nuestros saberes parcelados y aislados.

Confío haber mostrado en este artículo que las aportaciones de Edgar Morin no giran solo en torno a una o varias temáticas (epistemología, educación, teoría de la organización, diálogo entre biología y cultura), sino que su producción es una contribución generosa y múltiple a la humanidad, a la vida y a la Tierra, de cuya conciencia de unidad surge la propuesta de reorganizar el conocimiento para incidir, a su vez, en la reorganización de la sociedad. Cada una de sus obras, consistentemente, da cuenta de esa visión e intención integradoras.

La evaluación de los aportes de Morin se dará a lo largo del difícil tiempo por venir. Por lo pronto, los desafíos que tenemos sus lectores son los de evitar caer en el adoctrinamiento, no concebirnos como sus discípulos incondicionales, huir de la simplificación o reducción de sus ideas, de la cerrazón y de la falta de diálogo con otras tradiciones o fuentes de pensamiento, y asumir que sus ideas son y serán afectadas por el desgaste que causa el paso del tiempo. El mismo Edgar Morin lo ha advertido cada vez que tiene oportunidad: "un conocimiento que no se regenera, degenera". Así pues, los interesados en la obra de Morin, además de conocer realmente y con una profundidad mínima su obra, han de reflexionar críticamente sus ideas e indagar sus posibilidades de desarrollo. En eso consistiría el mejor homenaje que se le puede hacer a este lúcido pensador inconformista.

\section{Notas}

1. Existen algunos buenos estudios sobre las contribuciones de Edgar Morin a las ciencias sociales y humanas, por ejemplo: Argumentos para un método, publicación dirigida por David Bougneux, Jean-Luis Le Moigne y Serge Proulx (2005); los libros de Pedro Gómez García (2003) y de Alfredo Gutiérrez Gómez (1998 y 2003); y los trabajos de José Luis Solana Ruiz (1995, 1996, 1997, 1998a, 1998b, 2001, 2005 y 2011).

2. Un detallado libro, altamente recomendable, sobre la vida y obra de Edgar Morin es el de Emmanuel Lemieux (2011). También existen varias excelentes entrevistas realizadas a Morin como las realizadas por Tariq Ramadan, El peligro de las ideas (2014), Marie-Christine Navarro, publicada en el libro Itineránce (2000), y la conducida por Djénane Karh Tager (2008), que lleva por título Mi camino.

3. Un primer bosquejo de este escrito lo elaboré en un formato solicitado por una fundación y tres universidades para otorgarle un premio internacional a Edgar Morin en 2013.

4. En este artículo, entiendo por ciencias sociales a la sociología, la política, la economía, la historia y la antropología (con todas sus subcategorías y aplicaciones como educación, comunicación social, etc.); por ciencias humanas, a los ámbitos abarcados por la filosofía y los estudios culturales; y por humanidades, a los estudios religiosos, la teología, la literatura, la poesía, la música, el teatro y otros que son "fundamentales, en muchos casos, para comprender el mundo, la cultura y la naturaleza, en fin, la vida misma" (Maldonado 2016: 16 y 143). Sintetizo esos tres ámbitos de conocimiento bajo la expresión "ciencias sociales y humanidades".

5. Estas aportaciones de Morin, si bien pudieran ser entendidas cronológicamente, deberían concebirse como temáticas que tuvieron un énfasis en determinados períodos de su vida, pues están imbricadas, colaboran entre sí y son atraídas cuando alguna de ellas es reelaborada. Por otra parte, hablar de las contribuciones de Morin a las ciencias sociales y humanidades significa solamente eso, aportaciones. No significan, necesariamente, aportaciones originales.

6. La concepción transdisciplinar de Morin conduce a no identificar a este autor con una disciplina social específica y, a la vez, provoca que desde distintas ciencias o disciplinas se le ubique como antropólogo, sociólogo, comunicólogo, epistemólogo, filósofo o educador, por decir lo menos. Por tal motivo, he 
preferido referirme a sus contribuciones como trabajos antoposociológicos, pues el término remite a la dimensión inter y transdisciplinar de lo humano colectivo.

7. Sobre las herencias reconocidas por el mismo Morin y las interacciones entre ellas, véase su libro Mes philosophes (2011).

8. En muchas ocasiones, quienes dicen trabajar a partir del pensamiento complejo retoman solo tres principios básicos de la complejidad (el dialógico, el bucle recursivo, y el hologramático), sin conocer otros principios que acompañan al método que Morin propone. El riesgo de este proceder es caer en una nueva simplificación y en el reduccionismo, que es, precisamente, a lo que Morin se opone.

9. Morin, después de cuestionar algunas concepciones reduccionistas que se han dado de la transdisciplinariedad, entiende esta como un enfoque para "distinguir, separar, oponer y, por tanto, poner en relativa disyunción estos dominios científicos, pero que puedan ser que se comuniquen sin operar la reducción... ¿Cómo hacer que se comuniquen? Sugiero hace que se comuniquen en circuito (...) enraizar la esfera antroposocial en la esfera biológica (...) enraizar la esfera viviente en la physis (...). Pero, enraizamiento no es reducción" (Morin 1984a: 314-315). Para él la clave está en el diálogo, la cooperación y la coexistencia entre las ciencias y disciplinas, incluyendo los desafíos de los antagonismos y las divergencias entre ellas.

10. Respecto a este mismo tema, escribe Carlos Eduardo Maldonado (2017: 70-71): "No existe ninguna garantía de superioridad entre el mito y la ciencia, o entre a religión y la ciencia, o entre la metafísica y la ciencia. Y ciertamente no a priori. C. Levy-Strauss, desde la antropología ya dejo esto claramente establecido (La pensé sauvage). Las distinciones entre ciencia y mito son esencialmente de orden práctico o de efectividad: es preferible aquello 'que sirve'; y lo 'que sirve' es aquello que cura más y mejor las enfermedades o que estructura mejor la sociedad y el mundo, o bien, aquello que admite mayor economía de conceptos y mayor comprensibilidad, por ejemplo".

11. Estas etapas reorganizadoras del pensamiento de Morin no son del todo conocidas, y aun menos distinguidas por sus lectores o críticos. En ocasiones, se retoman citas o se hacen críticas a Morin sin conocer que él mismo ha hecho un replanteamiento de sus ideas.

12. Este libro, poco conocido dentro de los países de habla castellana, me ha sorprendido por la riqueza y profundidad de sus reflexiones.

13. Estos debates han aparecido en forma de libros; las últimas conversaciones se encuentran en el libro de Edgar Morin y Jean-Louis Le Moigne titulado L'intelligence de la complexité.

\section{Bibliografía}

Barrón, Juan Carlos

2013 "Reconstrucción del aprendizaje interdisciplinario: un viejo debate en un nuevo contexto", Interdisciplina, $\mathrm{n}^{\circ}$ 1: 131-140.

Bougneux, Daniel (y otros)

1990 En torno a Edgar Morin. Argumentos para un método. Coloquio de Cerisy. México D. F., Biblioteca Universidad Veracruzana, 2005.

Gómez del Llano, Ignacio

2005 Breviario de filosofía práctica. Madrid, Siruela.

Gómez, Pedro

2003 La antropología compleja de Edgar Morín. Homo complexus. Granada, Universidad de Granada.

Gutiérrez, Alfredo

2003 La propuesta I: Edgar Morin, conocimiento e interdisciplina. México D. F., Universidad Iberoamericana Ciudad de México.

2007 "Edgar Morin en la paz y la amistad”, en Rubén Reynaga (comp.), Edgar Morin. Homenaje al amigo 85 años. México D. F., Multiversidad Mundo Real Edgar Morin. 
Le Moigne, Jean-Louis

2012 Agir et penser en complexité avec Jean-Louis Le Moigne. Témoignages de mises en actes. Paris, L ' Harmattan.

Lemieux, Emmanuel

2009 "Complejidad de los sistemas sociales. Un reto para las ciencias sociales", Cinta Moebio, $\mathrm{n}^{\circ} 36$ : 146-157. www.moebio.uchile.cl/36/maldonado.html

2011 Edgar Morin. Vida y obra del pensador inconformista. Barcelona, Kairós.

Maldonado, Carlos Eduardo

2016 Complejidad de las ciencias sociales. Y de otras ciencias y disciplinas. Bogotá, Editorial Desde Abajo.

2017 "Tipología de modelos científicos de explicación. Ciencia y complejidad”, Sociología y tecnociencia, $\mathrm{n}^{\circ} 7$ (2): 58-72.

Morin, Edgar

1946 L'an zéro de l'Allemagne. París, La Cité Universelle.

1951 El hombre y la muerte. Barcelona, Kairós, 1994.

1956 El cine o el hombre imaginario. Barcelona, Paidós, 2001.

1957 Las estrellas del cine. Buenos Aires, Editorial Universitaria de Buenos Aires, 1966.

1959 Autocrítica. Barcelona, Kairós, 1976.

1962 L'espirit du temps. Essai sur la culture de masse. París, Armand Colin, 2009.

1967 La métamorphose de Plozevet. Commune en France. París, Pluriel, 2013.

1968 (con Claude Lefort y Cornelius Castoriadis), May 68. La Brèche suivi de Vingt ans après. París, Fayard, 2008.

1969a La rumeur d'Orléans. París, Éditions du Seuil.

1969b Introduction à une politique de l'homme. París, Éditions du Seuil, 1999.

1969c Le vif du sujet. París, Éditions de Seuil, 1983.

1970 Diario de California. Barcelona, Fundamentos, 1973.

1973 El paradigma perdido. Barcelona, Kairós, 1994.

1977 El método I: La naturaleza de la naturaleza. Madrid, Cátedra, 1986.

1978 (con Massimo Piattelli-Palmerini), L'Unité de l'homme: pour une anthropologie fondamentale. París, Éditions du Seuil, 3 vols.

1980 El método II: La vida de la vida. Madrid, Cátedra, 1983.

1981 Journal de un livre. París, Inter-Éditions.

1982 Para salir del siglo XX. Barcelona, Kairós.

1983 ¿Qué es el totalitarismo? De la naturaleza de la URSS. Barcelona, Anthropos, 1985.

1984a Ciencia con conciencia. Barcelona, Anthropos, 1988.

1984b Sociología. Madrid, Taurus, 1995.

1986 El método III: El conocimiento del conocimiento. Madrid, Cátedra, 1988.

1987 Pensar Europa. La metamorfosis de Europa. Barcelona, Gedisa, 1988.

1989 Vidal y los suyos. Barcelona, Galaxia Gutemberg, 2009.

1990a Introducción al pensamiento complejo. Barcelona, Gedisa, 1990.

1990b Arguments pour une méthode. Colloque de Cerisy. París, Éditions du Seuil.

1990c (y Patirick Viveret), ¿Cómo vivir en tiempos de crisis? Barcelona, Icaria, 2011.

1991 El método IV: Las ideas. Madrid, Cátedra, 1992.

1993 (y Anne Brigitte Kern), Tierra patria Buenos Aires, Nueva Visión.

1994a Mis demonios. Barcelona, Kairós, 1995.

1994b La complexité humaine. París, Flammarion.

1995 Une année Sisyphe. Journal de la fin du siècle. París, Éditions du Seuil. 1996a Les Fratricides (Yougoslavie-Bosnie, 1991-1995). París, Arléa

1996b Pleurer, aimer, rire, comprendre. París, Arléa.

1997a Amor, poesía y sabiduría. Barcelona, Seix Barral, 2011.

1997b (con Samir Amin), Para una política de civilización. Barcelona, Paidós, 2009.

1999a "Epistemología de la complejidad", en José Luis Solana, Con Edgar Morin, por un pensamiento complejo. Implicaciones interdisciplinares. Madrid, Universidad Internacional de Andalucía/AKAL, 2005.

1999b Los siete saberes necesarios para la educación del futuro. París, UNESCO.

1999c Relier les connaissances. Le défi du XXle siècle. Journées thématiques conçues et animées par Edgar Morin. París, Éditions du Seuil.

1999d La cabeza bien puesta. Repensar la reforma, reformar el pensamiento. Buenos Aires, Nueva Visión, 2008. (El mismo libro también apareció con el título La mente bien ordenada. Repensar la 
reforma. Repensar el pensamiento. Barcelona, Seix Barral, 2000).

1999e (con Jean-Louis Le Moigne), L'intelligence de la complexité. París, L'Harmattan.

2000a (con Boris Cyrulnik), Diálogos sobre la naturaleza humana. Barcelona, Paidós, 2005.

2000b (con Marie-Christine Navarro), Itinérance. París, Arléa, 2006.

2001 El método V: La humanidad de la humanidad. Madrid, Cátedra, 2003.

2002 Planeta, a aventura desconhecida. Sao Pablo, Unesp.

2003a (con Emilio Roger Ciurana y Raúl Domingo Motta), Éduquer pour l'ère planétaire: la pensée complexe comme méthode d'apprentissage dans l'erreur et l'incertitude humaines. París, Balland.

2003b (y Jean Baudrillard), La violencia en el mundo. Buenos Aires, Libros del Zorzal, 2004.

2004a El método VI: Ética. Madrid, Cátedra, 2006.

2004b Pour entrer dans le XXle siècle. París, Éditions du Seuil.

2006 (codirección con Jean-Lous Le Moigne), Intelligence de la complexité. Epistémologie et pratique. París, Éditions de l'Aube.

2007a (y Nicolas Hulot), El año I de la era ecológica Madrid, Paidós, 2008.

2007b Vers l'abime. París, Editions de L'Herne.

2008 (y Djénane Kareh Tager), Mi camino. La vida y la obra del padre del pensamiento complejo. Barcelona, Gedisa, 2010.

2009 Edwige, l'inseparable. París, Fayard.

2011a Mes philosophes. París, Pluriel, 2013.

2011b La vía para el futuro de la humanidad. México D. F., Paidós.

2011c (y Stéphane Hessel), El camino de la esperanza. Barcelona, Paidós, 2012.

2014a Enseigner á vivre. Manifeste pour changer l'éducation. París, Actes Sud.

2014b Au rythme du monde. Un demi-siècle d'articles dans Le Monde. París, Presses du Châtelet.

2014c (con Tariq Ramadan). Au péril des idées. Les grandes questions de notre temps: dialogue. París,

Presses du Chatelet.

2015a L'aventure de La Méthode. París, Seuil.

2015b Penser Global. París, Champs.

2016a Écologiser L'homme. París, Lemieux.

2016b Sur l'esthétique. París, Robert Laffont/Fondation Maison des Sciences de L'Homme.

Solana, José Luis

1995 "La unidad y diversidad del hombre en la antropología compleja de Edgar Morin", Gazeta de Antropología, $\mathrm{n}^{\circ}$ 11, febrero: 12-16.

1996 "Bioculturalidad y Homo demens. Dos jalones de la antropología compleja", Gazeta de Antropología, $\mathrm{n}^{\circ} 12$, octubre: 19-33.

1997 "Noología y ecología de las ideas: una sociología del conocimiento compleja", en Antonio Robles (comp.), Metasociología y teoría de la complejidad, Facultad de Ciencias políticas y Sociología de la Universidad de Granada, Granada: 47-66.

1998a "Cerebro, espíritu, conocimiento y psiquismo. Contribuciones desde la antropología compleja de Edgar Morin. Parte primera: principios epistemológicos, cómputo y conocimiento", Gazeta de Antropología, $\mathrm{n}^{\circ}$ 13, enero: 11-24.

1998b "Cerebro, espíritu, conocimiento y psiquismo. Contribuciones desde la antropología compleja de Edgar Morin. Parte segunda: actividades cogitantes y antropología psicoafectiva”, Gazeta de Antropología, $\mathrm{n}^{\circ}$ 14, octubre: 9-20.

2001 Antropología y complejidad humana. La antropología compleja de Edgar Morin. Granada, Comares Editorial/Universidad de Jaén.

2005 Con Edgar Morin, por un pensamiento complejo. Implicaciones interdisciplinares. Madrid, Universidad Internacional de Andalucía/Akal.

2011 "El pensamiento complejo de Edgar Morin. Críticas, incomprensiones y revisiones necesarias", Gazeta de Antropología, n² 27 (1), Artículo 09. 